\title{
Anatomical and Functional Basis of Pelvic Autonomic Nerves with Regard to Radical Hysterectomy
}

\author{
(1) Illker SELÇUKa, \\ (1) Illkan TATAR ${ }^{b}$, \\ (1) Emre HURic, \\ (D) Tayfun GÜNGÖR ${ }^{a}$ \\ aDepartment of Gynecologic Oncology, \\ Health Sciences University, \\ Zekai Tahir Burak Woman's Health \\ Training and Research Hospital, \\ Departments of \\ ${ }^{\mathrm{b} A n a t o m y,}$ \\ 'Urology, \\ Hacettepe University Faculty of Medicine, \\ Ankara, TURKEY
}

Received: 22.10.2018

Accepted: 26.11.2018

Available online: 15.01.2019

\section{Correspondence:}

Illker SELÇUK

Health Sciences University

Zekai Tahir Burak Woman's Health

Training and Research Hospital,

Department of Gynecologic Oncology,

Ankara, TURKEY

ilkerselcukmd@ hotmail.com

\begin{abstract}
Radical hysterectomy is a surgery performed to excise all the peri-cervical tissues that have been affected by the spread of cervical carcinoma. During this procedure, the pelvic autonomic nerves are mostly injured due to the resection of ventral, caudal and lateral parts of parametrium, thus resulting in deficiencies of urologic, anorectal, and sexual functions. The urologic complications, especially bladder atony, lead to the most common surgical morbidity. Superior hypogastric plexus, hypogastric nerve, pelvic splanchnic nerves, and inferior hypogastric plexus provide sympathetic and parasympathetic innervation to the pelvic viscera. Selective protection of these nerves would definitely improve bladder functions; this approach is known as a nerve-sparing radical hysterectomy. A detailed knowledge of pelvic autonomic nerves, with regard to anatomical and clinical perspective, will improve the surgical outcomes.
\end{abstract}

Keywords: Nerve sparing radical hysterectomy; cervical cancer; parametrium; inferior hypogastric plexus; parasympathetic

he term radical hysterectomy refers to a surgery performed to excise all the peri-cervical tissues, affected by the spread of cervical carcinoma. ${ }^{1}$ The term 'clear surgical margins' increases the radicality, and this kind of surgery results in high morbidities. Therefore, preservation of pelvic autonomic nerves has gained importance in improving functionality. ${ }^{2}$ Accurate definitions of surgical landmarks, from the point of anatomical terminology, would improve surgical outcomes. In 1974, Piver and Rutledge classified hysterectomy into five categories; however, the nomenclature was not simple enough to unify the anatomical landmarks in clinical practice. ${ }^{3}$ In 2008, Querleu and Morrow updated the terminology of radical hysterectomy in terms of the lateral extension; since it lacks a standardized approach and also does not state about the pelvic autonomic nerves. ${ }^{4}$ Soon in 2011, Cibula et al. reviewed the anatomical landmarks for radical hysterectomy and defined the parametrium to have three dimensions longitudinally and transversally. ${ }^{5}$ Querleu et al. reviewed and summarized the classification of radical hysterectomy in $2017 .^{6}$

During the radical hysterectomy, the ureter is dissected from the posterior sheath of broad ligament laterally and is unroofed from the parametrial tunnel. The bladder and rectum are mobilized; ventral, caudal and lateral parts of parametrium are excised completely while dissecting the cardinal ligament from the pelvic side wall and the uterosacral ligament from 
the sacrum. These anatomic structures are in close proximity to the pelvic sympathetic and parasympathetic nerve fibers; therefore, the major complications arising after radical hysterectomy are urological problems. Urinary dysfunction occurs as a result of pelvic autonomic nerve injury, damaged during the parametrial resection and uterosacral ligament excision, consequently affecting up to $20 \%$ of the patients. ${ }^{7}$

This article focuses on the anatomical and clinical role of pelvic autonomic nerves during radical hysterectomy.

\section{AUTONOMIC NERVOUS SYSTEM}

Autonomic nervous system (ANS) functions involuntarily and controls the smooth muscles present on the wall of internal organs (pupils, blood vessels, heart, lungs, liver, stomach, intestines, bladder, genitalia, etc.), cardiac muscles and also the exocrine glands, via the hypothalamus. Sympathetic and parasympathetic systems are the two main courses of the ANS (the enteric system is also considered a part of the ANS). The ANS regulates the pupillary reflex, heart and respiratory rate, blood pressure, digestive, urinary and sexual functions. Besides the afferent pathways, the efferent pathways of ANS innervate the visceral organs with presynaptic (preganglionic) and postsynaptic (postganglionic) neurons, which synapse at the ganglia.

The neurons of the sympathetic nervous system (SNS) are located at the medulla spinalis, between Thoracal (T) 1 and Lumbar (L) 2 segments. Some preganglionic axons of the sympathetic system adjoin the postganglionic axons at the sympathetic trunk, formed by the paravertebral ganglions (cervical, thoracal/lumbar and sacral ganglia) located at both sides of the vertebra. These postganglionic neurons bring about non-visceral sympathetic innervations. However, some sympathetic nerve fibers comprise splanchnic nerves, which synapse at the prevertebral ganglions (celiac, aorticorenal, superior mesenteric, and inferior mesenteric ganglia) and are responsible for sympathetic innervation of the abdominal viscera. The network of nerve fibers in close proximity to the prevertebral ganglia forms the prevertebral plexus (celiac, aortic, and superior hypogastric plexus) (Figure 1).

The neurons of the parasympathetic nervous system (PNS) are located at the brain stem and medulla spinalis between the second and fourth sacral (S) segments. The preganglionic nerve fibers

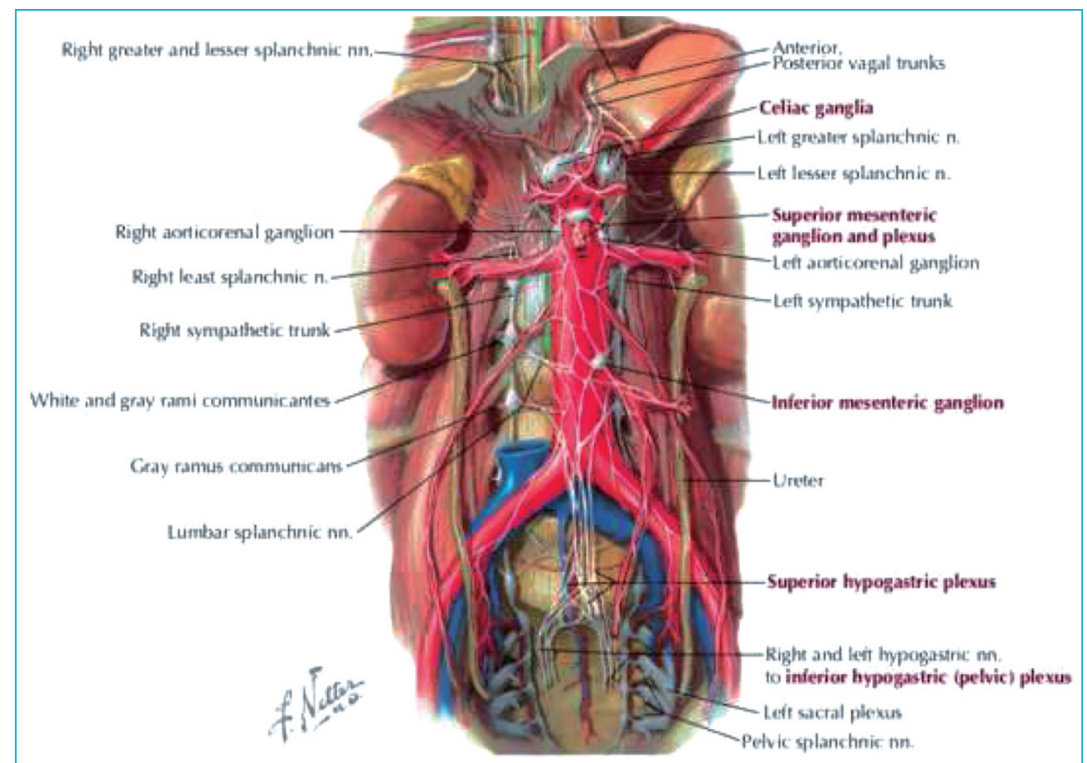

FIGURE 1: Abdominal autonomic nerves (From Atlas of human anatomy, ed 6, Plate 297) (Netter's Clinical Anatomy, 3rd Edition, Saunders/Elsevier, 2014, Atlas of Human Anatomy, 6th Edition, Saunders/Elsevier, 2014). 
of PNS accompany the motor neurons of the sacral spinal nerves. Before exiting the spinal nerves, they form the pelvic splanchnic nerves and join the inferior hypogastric plexus. Ultimately, they form the terminal ganglion near the target organ.

\section{PELVIC AUTONOMIC INNERVATION}

Superior hypogastric plexus (SHP) is located anterior to the aortic bifurcation at the L5 level, runs downward infero-laterally, medial to the internal iliac vessels where it is then named as the hypogastric nerve (HN). This forms the most important pathway connecting the sympathetic fibers to the pelvic viscera. Pelvic splanchnic nerves (PSN), which carry the preganglionic parasympathetic fibers from S2 to S4, are responsible for the parasympathetic innervation of pelvic viscera. They join the hypogastric nerves bilaterally and are named as the inferior hypogastric plexus (IHP) along the course (Figure 2). Later, terminal branches of the inferior hypogastric plexus penetrate into the deep perineal plates of the pelvic viscera and serve as sub-plexus (rectal, utero-vaginal, and vesical plexus).

\section{CLINICAL FUNCTIONS OF PELVIC AUTONOMIC INNERVATION}

\section{SYMPATHETIC INNERVATION}

Sympathetic innervation arising from T10 to L2 segments serves as the postganglionic fibers of inferior hypogastric plexus, which is formed by the hypogastric nerve and sacral splanchnic nerves. Sympathetic nerves are responsible for:

Innervation of blood vessels,

- Contraction of internal urethral sphincter and internal anal sphincter, and

- Contraction of smooth muscles along the reproductive tract and the accessory glands of the reproductive system

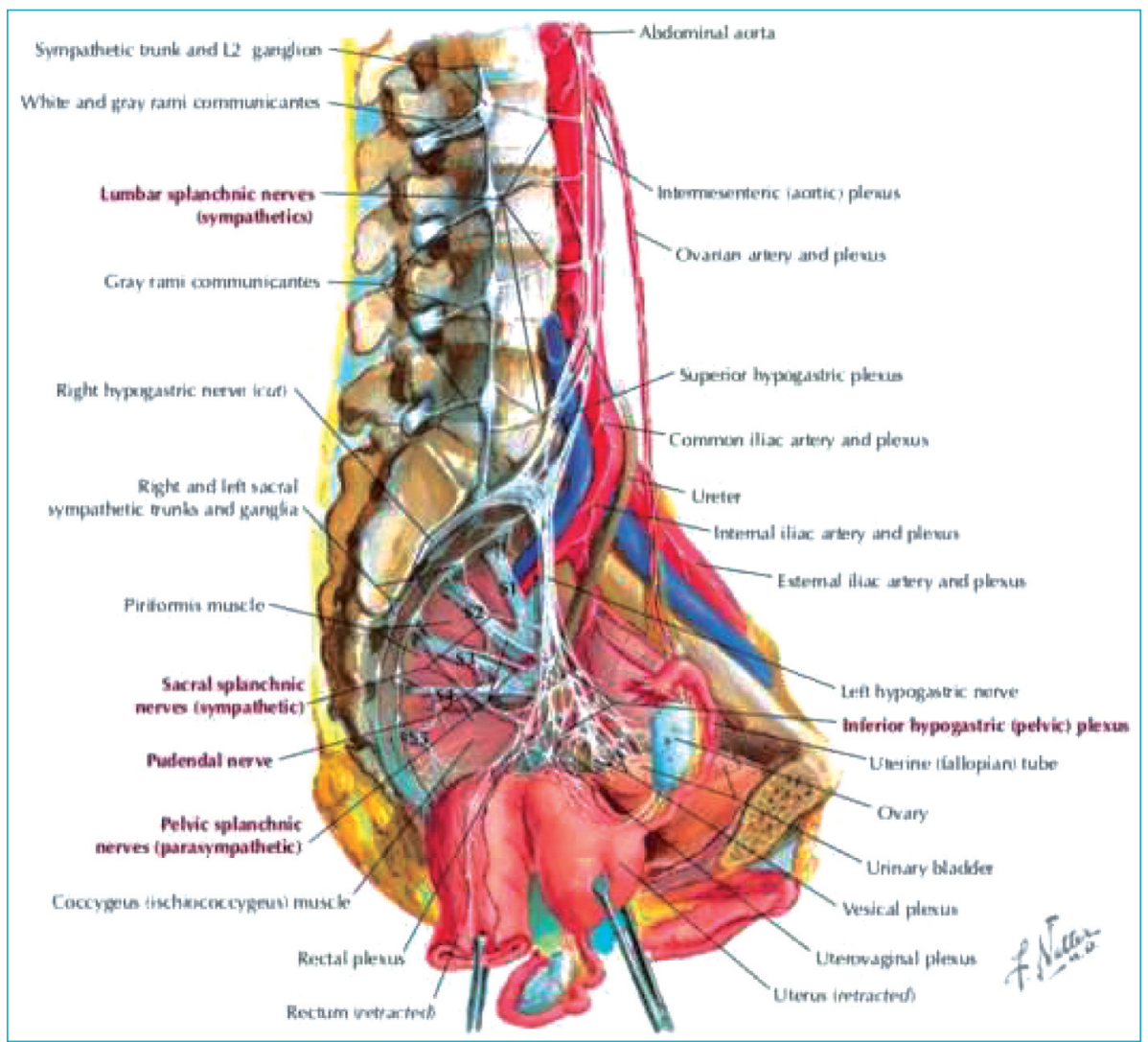

FIGURE 2: Nerves of the pelvic cavity (From Atlas of human anatomy, ed 6, Plate 390) (Netter's Clinical Anatomy, 3rd Edition, Saunders/Elsevier, 2014, Atlas of Human Anatomy, 6th Edition, Saunders/Elsevier, 2014). 


\section{PARASYMPATHETIC INNERVATION}

The parasympathetic nerves join the inferior hypogastric plexus with pelvic splanchnic nerves originating from S2 to S4. They are responsible for:

- Vasodilatory effects,

- Stimulation of bladder contraction, and

- Controlling the activity of the enteric nervous system of the distal colon, left colic flexure and pelvic viscera

\section{PHYSIOLOGY OF BLADDER FUNCTION}

The coordinated mechanism of the sympathetic and parasympathetic system helps in the emptying of the bladder when it is full. This is facilitated by the smooth muscle contraction of the bladder. The sensory sympathetic nerve fibers transmit the sensation of bladder expansion, originating from the trigone or peritoneum over the bladder, toward the sympathetic chain of splanchnic nerves at $\mathrm{T} 12$. The sympathetic motor fibers inhibit the dominance on bladder while the parasympathetic ganglion acts to contract the bladder muscles. Consequently, injury to the motor parasympathetic nerves disrupts the function of the detrusor muscle of the bladder, which results in the atonic bladder.

\section{CLINICAL ANATOMY FOR NERVE-SPARING RADICAL HYSTERECTOMY (NSRH)}

The nerve-sparing approach of radical hysterectomy aims at maintaining urinary functions as well as sexual and anorectal functions. Superior hypogastric plexus is a preaortic network of pre-postganglionic nerve fibers arising from the sympathetic trunk. It forms the hypogastric nerve on each side of the sacral promontorium, $1 \mathrm{~cm}$ lateral to the midline and 2c m medial to the ureter and internal iliac vessels (Figure 3). ${ }^{8}$ During the development of pararectal space anterolateral to the presacral area, these nerve fibers are found on the posterolateral part of the rectum. The pelvic splanchnic nerves arising from the ventral roots of S2-S4 enter the pelvis through the sacral foramina by crossing the retrorectal space and lie on the lateral part of the rectum (uterosacral ligament), $4 \mathrm{~cm}$ lateral to the midline. ${ }^{8,9}$ They merge with the hy- pogastric nerve during the course, and the plexus so formed is, therefore, named as the inferior hypogastric plexus. The inferior hypogastric plexus is composed of hyposgastric nerve, splanchnic nerves of the sacral sympathetic trunk, and pelvic splanchnic nerves. IHP, therefore, transmits sympathetic and parasympathetic nerve fibers. The middle rectal artery, an anatomic landmark, passes through the deep lateral part of the pararectal space. Just inferior to this the pelvic splanchnic nerves lies, which are primarily responsible for detrusor contractility, vaginal lubrication, and genital swelling during sexual arousal. This is due to the adrenergic and cholinergic activity. ${ }^{10,11}$

The pararectal fascia and perirectal adipose tissue form a line that helps to identify the IHP, which runs anterolaterally to the rectum. The most medial part of the nerve fibers that constitute the IHP runs along the uterosacral ligament. The nerve fibers of IHP pass laterally to the cervix and the vaginal fornix, moving forwards toward the base of the bladder. During this course, the nerve fibers of IHP are positioned medial to the vascular layer of parametrium and deep to the peritoneum; the posterior part supplies the rectum; and while accompanying the ureter and other close arteries, the

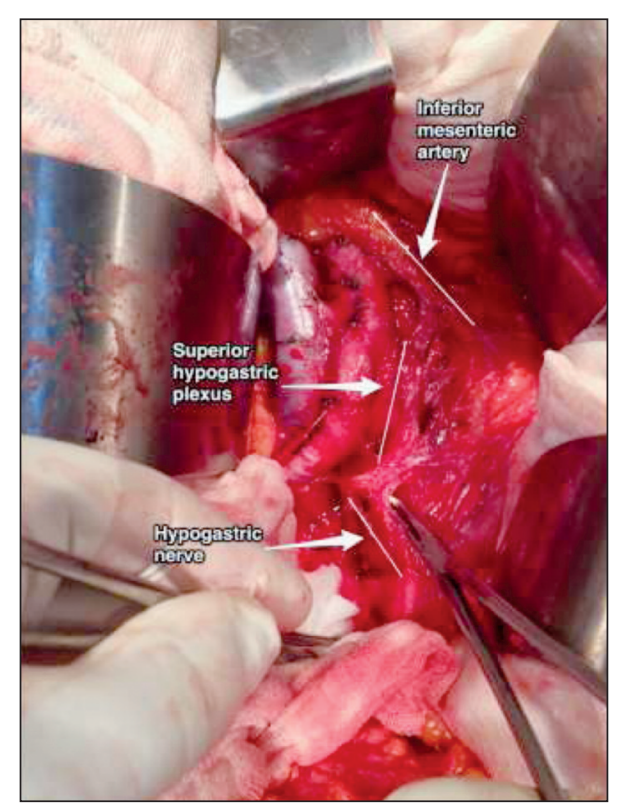

FIGURE 3: Superior hypogastric plexus and hypogastric nerve (nerve sparing radical hysterectomy-cervical cancer patient). 
nerve fibers lie deep within the ureter and inferolateral to the bladder (Figure 4). ${ }^{12,13}$ The terminal ganglia near the target organ, which are an extension of IHP, consists sympathetic and parasympathetic efferent fibers innervating the bladder, ureter, uterus, and vagina. ${ }^{9}$

After all, the pelvic sub-plexuses are the most important nerve units that preserve the urinary functions. They are located close to the target organ (extending from the lateral part of the vagina to the vesicovaginal septum and trigon of the bladder), hence a careful dissection is mandatory during the excision of the peri-cervical tissues close to the vaginal fornix, especially vesico-uterine ligament.

\section{METHODOLOGY FOR PRESERVING PELVIC AUTONOMIC NERVES}

After developing the pararectal space, the hypogastric nerve can easily be identified posterolateral to the rectum and anterior to the promontorium. After the recto-vaginal space is opened by an incision on the peritoneum of Douglas, the uterosacral ligament and recto-vaginal pillars can be identified while the rectum is mobilized postero-medially. Following the course of the hy-

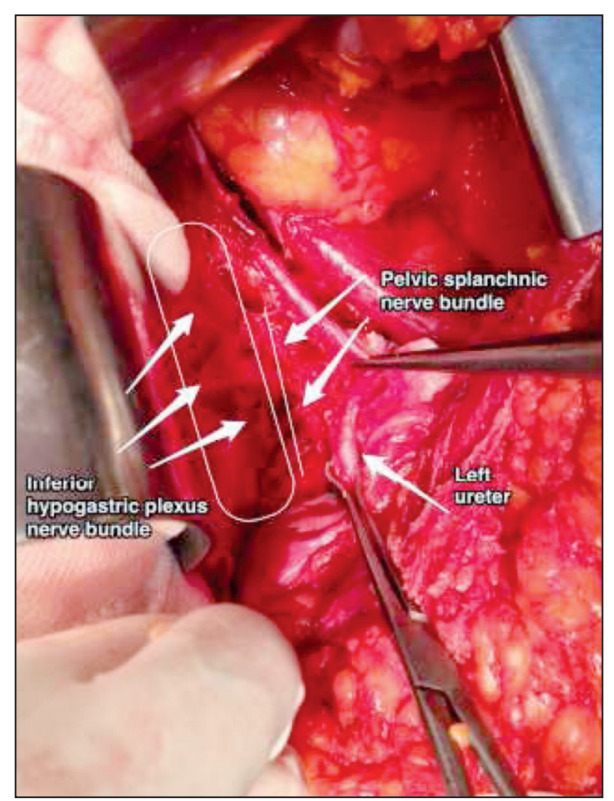

FIGURE 4: Inferior hypogastric plexus nerve bundle and pelvic splanchnic nerve bundle (nerve sparing radical hysterectomy-cervical cancer patient). pogastric nerve would also offer a selective protection for the inferior hypogastric nerve on the lateral part of the uterosacral ligament.

While dissecting the ureter laterally from the ureteric tunnel with its surrounding fatty tissue and neurovascular bundle, the terminal branches of pelvic splanchnic nerves located at the lower portion of ureter can be preserved. Nevertheless, when the ureteric tunnel is opened and the vesico-uterine ligament is excised, some veins and nerves of the vesical plexus will definitely be sacrificed. Proper dissection of the distal ureter is the most important point in preserving bladder functions. ${ }^{14}$ Shingo Fujii highlighted the major role of vesicouterine ligament dissection (posterior part) for achieving a complete nerve-sparing radical hysterectomy. ${ }^{15}$

During the dissection of the lateral parametrium, deep uterine vein (an anatomic landmark) can be detected at the lower part of the uterine artery. Also, the pelvic splanchnic nerves arising from the sacral promontorium can be identified just beneath the deep uterine vein. ${ }^{16}$ So, dissection under the deep uterine vein will damage the pelvic splanchnic nerves.

\section{CONCLUSION}

\section{HIGH RISK KEY ZONES FOR PELVIC AUTONOMIC NERVE INJURY DURING RADICAL HYSTERECTOMY}

Bladder dysfunction results either from the loss of sensation or failure of contraction of the bladder muscle (detrusor) or both. The proper knowledge of anatomic landmarks and neural compartments in the pelvis is a must in order to conserve the nerve conduction to the bladder and rectum.

A radical hysterectomy involves various steps where pelvic autonomic nerves may be injured and a meticulous dissection is therefore needed (Figure 5): ${ }^{16-20}$

Hypogastric nerves can be injured during resection of the uterosacral ligament at the posterior pelvic wall (lateral to rectum).

Pelvic splanchnic nerves may be injured during dissection of lateral parametrium and lymph nodes, infero-medial to the internal iliac vein beneath the deep uterine vein. 


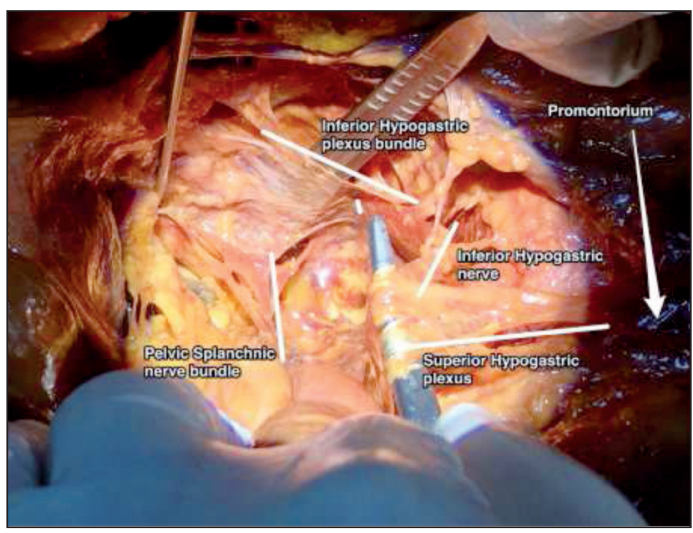

FIGURE 5: Pelvic autonomic nerves (cadaveric dissection).

Vesical branches arising from the vesical subplexus (mainly originated from inferior hypogastric plexus) can be injured during resection of vesicouterine ligament and ventral parametrium.

Rectal and utero-vaginal sub-plexus arising from the inferior hypogastric plexus may be injured during mobilization of the rectum after opening the recto-vaginal space, dissection of uterosacral ligament and resection of the vagina.

\section{Acknowledgement}

We would like to thanks Health Sciences University, Zekai Tahir Burak Woman's Health Education and Research Hospi- tal, Ankara/Turkey, and Pelvic Reconstructive and Functional Urology Surgery Cadaveric Workshop, 22-23 April 2017, Bahcesehir University Faculty of Medicine, Prof. Rhoton Anatomy Laboratory, Istanbul/Turkey.

\section{Source of Finance}

During this study, no financial or spiritual support was received neither from any pharmaceutical company that has a direct connection with the research subject, nor from a company that provides or produces medical instruments and materials which may negatively affect the evaluation process of this study.

\section{Conflict of Interest}

No conflicts of interest between the authors and / or family members of the scientific and medical committee members or members of the potential conflicts of interest, counseling, expertise, working conditions, share holding and similar situations in any firm.

\section{Authorship Contributions}

Idea/Concept: İlker Selçuk; Design: İlker Selçuk, Emre Huri; Control/Supervision: Emre Huri, Tayfun Güngör; Data Collection and/or Processing: Illker Selçuk, İlkan Tatar; Analysis and/or Interpretation: İlker Selçuk, İlkan Tatar, Emre Huri, Tayfun Güngör; Literature Review: İlker Selçuk, İlkan Tatar; Writing the Article: IIlker Selçuk; Critical Review: Emre Huri, İlkan Tatar, Tayfun Güngör; References and Fundings: Emre Huri, Tayfun Güngör, İlkan Tatar; Materials: Emre Huri, Tayfun Güngör.

\section{REFERENCES}

1. Swailes AL, Gockley A, Phaëton R, Kesterson JP. The Wertheim hysterectomy: development, modifications, and impact in the present day. Gynecol Oncol 2017;145(1):3-8.

2. Maas CP, Trimbos JB, DeRuiter MC, van de Velde CJ, Kenter GG. Nerve sparing radical hysterectomy: latest developments and historical perspective. Crit Rev Oncol Hematol 2003;48(3):271-9.

3. Piver MS, Rutledge F, Smith JP. Five classes of extended hysterectomy for women with cervical cancer. Obstet Gynecol 1974;44(2):26572.

4. Querleu D, Morrow CP. Classification of radical hysterectomy. Lancet Oncol 2008;9(3): 297-303.

5. Cibula D, Abu-Rustum NR, Benedetti-Panici P, Köhler C, Raspagliesi F, Querleu D, et al. New classification system of radical hysterectomy: emphasis on a three-dimensional anatomic template for parametrial resection.
Gynecol Oncol 2011;122(2):264-8.

6. Querleu D, Cibula D, Abu-Rustum NR. 2017 update on the querleu-morrow classification of radical hysterectomy. Ann Surg Oncol 2017;24(11):3406-12.

7. Ware RA, van Nagell JR. Radical hysterectomy with pelvic lymphadenectomy: indications, technique, and complications. Obstet Gynecol Int 2010;2010. Doi: 10.1155/2010/ 587610.

8. Daniels IR, Woodward S, Taylor FG, Raja A, Toomey P. Female urogenital dysfunction following total mesorectal excision for rectal cancer. World J Surg Oncol 2006;4:6.

9. Moszkowicz D, Alsaid B, Bessede T, Penna C, Nordlinger B, Benoît G, et al. Where does pelvic nerve injury occur during rectal surgery for cancer? Colorectal Dis 2011;13(12):132634.

10. Trimbos JB, Maas CP, Deruiter MC, Peters $A A$, Kenter GG. A nerve-sparing radical hys- terectomy: guidelines and feasibility in Western patients. Int $\mathrm{J}$ Gynecol Cancer 2001;11(3):180-6.

11. Sato $K$, Sato $T$. The vascular and neuronal composition of the lateral ligament of the rectum and the rectosacral fascia. Surg Radiol Anat 1991;13(1):17-22.

12. Baader B, Herrmann M. Topography of the pelvic autonomic nervous system and its potential impact on surgical intervention in the pelvis. Clin Anat 2003;16(2):119-30.

13. Spackman R, Wrigley B, Roberts A, Quinn M. The inferior hypogastric plexus: a different view. J Obstet Gynaecol 2008;28(1):141-2.

14. Kraima AC, Derks M, Smit NN, van de Velde CJ, Kenter GG, DeRuiter MC. Careful dissection of the distal ureter is highly important in nerve-sparing radical pelvic surgery: a 3D reconstruction and immunohistochemical characterization of the vesical plexus. Int $\mathrm{J}$ Gynecol Cancer 2016;26(5):959-66. 
15. Fujii S. Anatomic identification of nerve-sparing radical hysterectomy: a step-by-step procedure. Gynecol Oncol 2008;111(2 Suppl): S33-41.

16. Fujii S, Takakura K, Matsumura N, Higuchi T, Yura S, Mandai M, et al. Anatomic identification and functional outcomes of the nerve sparing Okabayashi radical hysterectomy. Gynecol Oncol 2007;107(1):413.
17. Sakuragi N, Todo $Y$, Kudo M, Yamamoto $R$, Sato $T$. A systematic nerve-sparing radical hysterectomy technique in invasive cervical cancer for preserving postsurgical bladder function. Int J Gynecol Cancer 2005; 15(2):389-97.

18. Dursun $P$, Ayhan A, Kuscu E. Nerve-sparing radical hysterectomy for cervical carcinoma. Crit Rev Oncol Hematol 2009;70(3):195205.
19. Díaz-Feijoo B, Bradbury M, Pérez-Benavente A, Franco-Camps S, Gil-Moreno A. Nervesparing technique during laparoscopic radical hysterectomy: critical steps. J Minim Invasive Gynecol 2018;25(7):1144-5.

20. Charoenkwan K. A simplified technique for nerve-sparing type III radical hysterectomy: by reorganizing their surgical sequence, surgeons could more easily identify key nerves. Am J Obstet Gynecol 2010;203(6):600.e1-6. 